\title{
Agôn
}

Revue des arts de la scène

Critiques | Saison 2010-2011

\section{Supposons pour le moment, on changera tout si ça marche pas}

Robert Cantarella fait le Gilles à la Ménagerie de Verre

\section{Barbara Métais-Chastanier}

\section{(2) OpenEdition}

Journals

Édition électronique

URL : http://journals.openedition.org/agon/1683

DOI : 10.4000 /agon. 1683

ISSN : 1961-8581

Éditeur

Association Agôn

Référence électronique

Barbara Métais-Chastanier, "Supposons pour le moment, on changera tout si ça marche pas », Agôn

[En ligne], Critiques, mis en ligne le 13 mai 2011, consulté le 23 septembre 2020. URL : http://

journals.openedition.org/agon/1683; DOI : https://doi.org/10.4000/agon.1683

Ce document a été généré automatiquement le 23 septembre 2020.

Association Agôn et les auteurs des articles 


\title{
Supposons pour le moment, on changera tout si ça marche pas
}

\author{
Robert Cantarella fait le Gilles à la Ménagerie de Verre
}

\author{
Barbara Métais-Chastanier
}

1 Robert Cantarella, pendant un an, va donner à entendre - oreillettes vissées sur les oreilles et archive sonore délayée dans le tympan - le séminaire de Gilles Deleuze de 1981 consacré à l'« Image-Mouvement ». L'ancien directeur du 104, également metteur en scène, remet à flot un exercice qu'il avait déjà pratiqué rue d'Aubervilliers avec le philosophe, se livrant à son séminaire sur Spinoza de 1981, et avec d'autres penseurs à la manière moins déliée. Inutile de chercher les tables encastrées, les chaises adossées, le brouhaha des fenêtres closes et l'îlot de fumée des salles de Vincennes, c'est la Ménagerie de Verre qui lui ouvre ses portes et ses espaces blancs tous les premiers lundi du mois. Emportée double dans la salle, dans la voix et la pensée qui sont ici inextricablement liées, si bien qu'assis - spectateurs, auditeurs, disciples, nostalgiques, flâneurs cinéphiles, ou simples curieux - on ne sait plus vraiment qui on vient écouter (les réponses dans la salle seraient sans doute diverses) ni qui on vient voir : et pourtant le seul corps en présence est bien celui de Robert Cantarella, tendu sur sa chaise, bondissant dans son immobilité, où se creuse, sans qu'on y prenne garde, un autre corps, le corps absent, qui survient par moment, s'efface, se retire, se pose en surimpression sur les traits donnés à voir. Deleuze ? Cantarella? Un mixte des deux où se fomenterait quelque chose du bouillon théâtral et de la physionomie d'une pensée?

2 Plus encore que ce terrible qui (où se complique pourtant l'affaire), le doute grandit sur ce que l'on vient voir - et contamine très vite la suite de la proposition : on finit par ne plus savoir si on vient vraiment voir quelque chose. Conférence performée ? acteur à la besogne? cours exhumé ? séminaire vocalisé, compilé et sitôt réingéré par un bon vieux corps? Un peu de tout ça sans doute si on prend le parti de lire le visage de ce qui se donne à voir sur les traits de ceux qui viennent y assister. Car dans la salle, au déplaisir de certains - qui leur jettent un œil noir quand ce n'est pas tout bonnement une giclée de colère -, on trouve des cahiers, des claviers, des petits papiers, des crayons et tout ce qui fait que fiévreusement sont prises en note, en fiches, en 
paragraphes recomposés d'axes, d'idées et d'exemples, et que sont consignées et alignées à nouveau, les archives sonores des cours de Deleuze. Ça fait du bruit. Ça chuinte. Ça fuit. Ça tapote. Ça appuie sur des touches. Ça prend des photos. Ça filme des petits bouts à la volée ou plus franchement. Ça note une phrase ou deux. Ça hoche de la tête. Ça n'est pas d'accord. Ça se tend quand ça se complique. Ça se relâche quand la pensée s'écoule. Le corps n'est pas là comme il est au théâtre: la chair retrouve instinctivement quelque chose de l'écoute du cours - attention flottante ou ciblée, concentration prédatrice, méticuleuse, bigote ou plus franchement brouillonne et vagabonde. Certains consciencieux ont pris la peine de relire les chapitres de Bergson, de parcourir assoiffé Matière et Mémoire, de feuilleter L'Évolution créatrice. D'autres, plus scrupuleux encore, les arborent avec fierté, les posent, rassurés, assis à côté d'eux, racornis, fatigués, les feuillètent et les reprennent pendant les deux heures que dure la rencontre de Robert et de Gilles.

\section{Faire le Gilles, de Robert Cantarella}

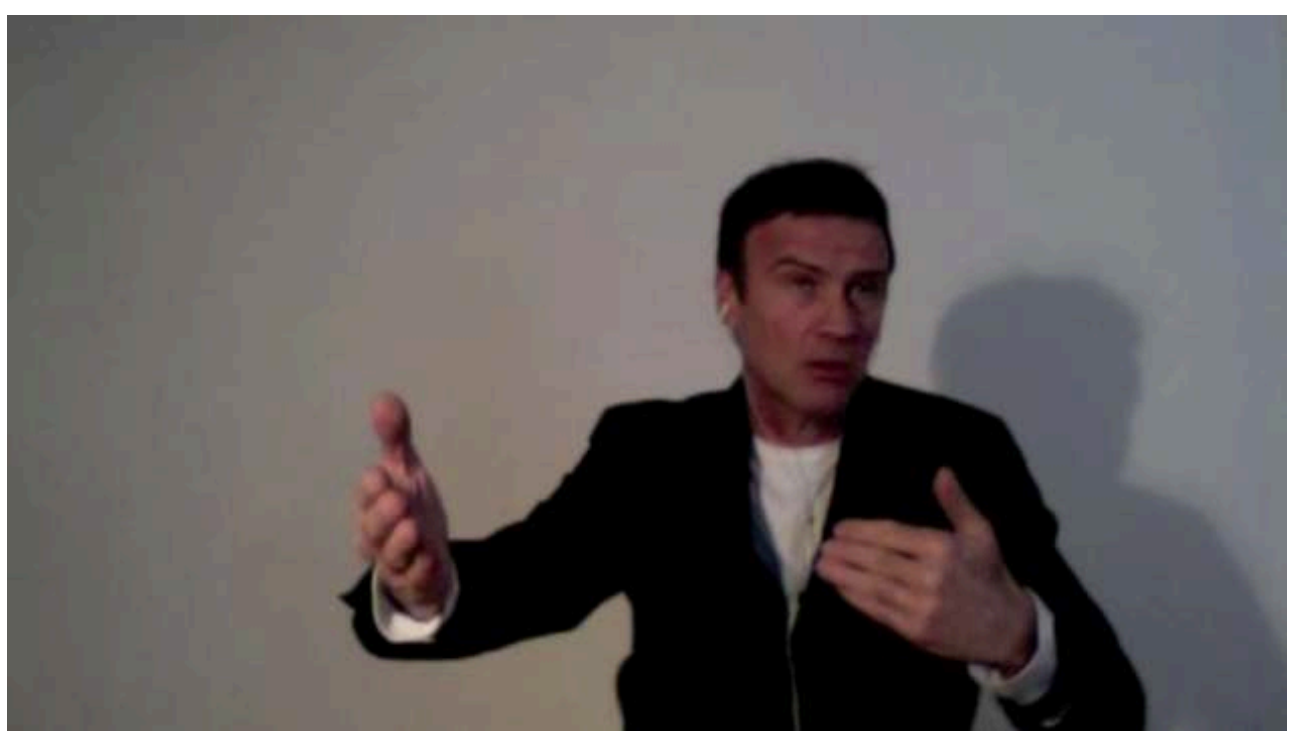

(C) DR

3 En plus de ces corps qui rejouent sans savoir l'écoute du séminaire - il y a le complice. Délégué discret à la fabrique de l'époque : Alexandre Meyer, oreillettes vissées lui aussi, est la voix soufflée - celle des chuintements inaudibles de l'enregistrement (les bandes étaient mauvaises), celle des quintes de toux (on y fumait en continu et de concert), des ambiances étouffées (interdiction d'ouvrir les fenêtres), des petits airs chantonnés, celle qui se noue aux ricanements ("Cesse de te marrer tout le temps, c'est agaçant, je n'arrive plus à réfléchir.»), et qui provoque les interruptions (« Non ...non. Il ne faut pas me troubler, il faut retenir cette question puisque dans... »), les objections (« Mais non tu dis ça pour me contrarier, t'es pas hégélien du tout. »), les corrections (« Ce n'est pas Billy non... ce n'est pas Billy? C'est Billy?»), les reports ("Je réclame une fois de plus toute votre patience. »), les dispersions («Il me fait taire une idée. »), les prises de pouvoir ( $\mathrm{Tu}$ voudrais parler alors très bien, alors on va parler hein. »), les désastres ( Je crois d'une manière très simple et toute modeste que je suis complètement en train - mais tout peut s'arranger mais je suis en train de rater ce que je me proposais.»), les épuisements («Est-ce que vous êtes fatigués ou vous êtes pas 
fatigués?»), les accords (« Ouais, ouais ouais ouais »), et les relances (« Bon vous avez encore un peu de courage ? Ou pas, on peut arrêter là hein.)

4 La sobriété du dispositif nous jette de plain-pied dans la pensée, dans ses conditions d'exercice en tant qu'elle opère dans un corps et se donne par une voix. On dira, un peu trop rapidement peut-être, que le théatre, celui qui s'adosse à un texte, caresse le fantasme ou la noble ambition de retrouver les conditions d'exercice d'une écriture en marche, de gagner au présent ce qui est toujours et déjà derrière lui, ou jeté au-devant. Ici, pas d'écriture. La trace antérieure dans laquelle se coule l'acteur, celle qu'il suit dans ses inflexions, ses hoquètements, ses retours, ses bifurcations, ses étouffées, ses chuintements et ses chaos, c'est le phrasé d'une pensée. Robert Cantarella ne joue pas. Il n'imite pas Deleuze. Il se prête à un rythme, plus encore qu'à une prononciation : " Les concepts ont des vitesses et des lenteurs, des mouvements, des dynamiques qui s'étendent ou se contractent à travers le texte : ils ne renvoient plus à des personnages, mais sont eux-mêmes personnages, personnages rythmiques. Ils se complètent ou se séparent, s'affrontent, s'étreignent comme des lutteurs ou des amoureux. C'est la voix de l'acteur qui trace ces rythmes, ces mouvements de l'esprit dans l'espace et le temps. L'acteur est l'opérateur du texte; il opère une dramatisation du concept, la plus précise, la plus sobre, la plus linéaire aussi. Presque des lignes chinoises, des lignes vocales ${ }^{1}$.

Il y aurait en somme deux façons d'aborder l'énigme du ce que : la première, celle du philosophe - qui se demanderait sans doute ce que l'acteur peut bien apporter à la philosophie pour tenter de saisir ce que la voix donne comme corps à une pensée. La seconde, celle de l'acteur - qui lui pourrait s'interroger sur ce que la philosophie peut faire au théâtre, ce que le concept, dans ses déplacements, ses avancées soudaines, sa façon bien à lui d'occuper le temps, entraîne comme déplacements du point de vue de la scène. La première est celle que choisit Deleuze dans « Ce que la voix apporte au texte ", écrit en hommage à Alain Cuny - immense acteur et compagnon de route de Jean Vilar dès ses débuts - et publié dans la revue du Théâtre National Populaire en 1987. La seconde, c'est celle qu'adopte Cantarella quand il écrit : "Pour ce qui est de Deleuze le sens en marche se constitue au fur et à mesure que la matière de sa pensée vocale prend consistance dans la conscience de l'auditeur. Donc, je refais le chemin en sens inverse et espère retrouver le courant de l'inspiration, de l'hésitation, de la claudication de tout ce qui fait une pensée en train d'être partagée. » Selon que l'on soit philosophe ou acteur, on ne regardera sans doute pas du même œil les pérégrinations de Robert Cantarella à la Ménagerie de Verre. Là où les regards se rejoindront peutêtre, c'est autour de la brûlante évidence qui nous rappelle - si besoin était - que le théâtre peut participer lui aussi à l'érosion de la bêtise, y compris dans son propre champ, et mettre en marche une pensée active capable de faire lever en elle les conditions physiques de son entrainement.

6 Tous les premiers lundi du mois, Robert Cantarella reprend les cours de Deleuze à la Ménagerie de Verre : 4 avril, 2 mai, 6 juin, 4 juillet, 5 septembre, 3 octobre, 7 novembre, 5 décembre 2011 et 2 janvier, 6 février, 5 mars 2012 à 18 heures. 


\section{NOTES}

1. Gilles Deleuze, "Ce que la voix apporte au texte ", Deux régimes de fous, Paris, Éditions de Minuit, coll. « Paradoxe», 2003. pp. 303-304.

INDEX

Mots-clés : Cantarella (Robert), Deleuze (Gilles), Faire le Gilles 